\title{
Acute insulin response to intravenous glucose, glucagon and arginine in some subjects at risk for Type 1 (insulin-dependent) diabetes mellitus
}

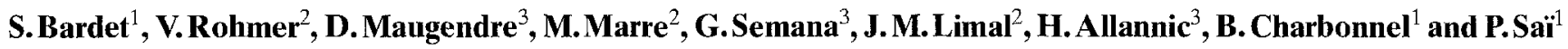 \\ 1 Clinique d'Endocrinologie et Laboratoire d'Immunologie du Diabète, Centre Hospitalo-Universitaire, Nantes, \\ 2 Services de Médecine B et C, Service de Pédiatrie, Centre Hospitalo-Universitaire, Angers, \\ ${ }^{3}$ Service d'Endocrinologie et Centre de Transfusion Sanguine, Centre Hospitalo-Universitaire, Rennes, France
}

\begin{abstract}
Summary. The relationships between first-phase insulin secretion to i.v. glucagon and i.v. arginine were studied in 19 healthy adult volunteers (Group I) and in 21 subjects at risk for Type 1 (insulin-dependent) diabetes mellitus with either a "normal" ( $n=11$; Group II a) or a "low" insulin response to i.v. glucose ( $n=10$; Group II b). Groups I and II a displayed similar insulin responses to the three secretagogues. In contrast, Group IIb demonstrated lower insulin responses to both glucagon and arginine than control subjects $(p<0.007$ and $p<0.04$ respectively) or than "normo-responders" to glu$\operatorname{cose}(p<0.007$ and $p<0.04$ respectively). In Group II b however, arginine-stimulated insulin release was increased compared to the response to glucose $(p<0.006)$, while glucagon and glucose led to non-statistically different responses. Five "low-responders" developed Type 1 diabetes. As a group, they displayed lower responses to glucagon and to arginine than subjects who up to now have not developed the disease $(p<0.05$ and $p<0.0003$ respectively). In the subjects who progressed to diabetes, the responses to glucose and glucagon
\end{abstract}

Type 1 (insulin-dependent) diabetes mellitus is a genetically programmed autoimmune disease due to the selective destruction of the pancreatic Beta cells [1].

The onset of diabetes is preceded by a latent period that can be detected by immune markers such as islet-cell antibodies (ICA) [2, 3], anti-64 Kd antibodies [4, 5] or insulin-autoantibodies (IAA) [6,7]. Additionally, metabolic abnormalities can also be detected during this prediabetic period. Basically, slightly elevated basal glucose values may identify the eminent onset of the disease [8]. Impaired oral glucose tolerance may precede the onset of the disease in identical twins of Type 1 diabetic patients [9]. The progressive loss of acute insulin response (AIR) to i.v. glucose may be an early event of this pre-diabetic state [10], as well as the defect for glucose to potentiate arginine-induced insulin release [11]. Finally, the decrease of AIR to secretagogues other than glucose has been described in early Type 1 diabetes [12]. were similarly blunted. In the "low-responders" who have not developed the disease, no statistical difference could be detected between mean responses to glucagon and glucose, but four out of these five subjects had a glucagon-stimulated response within the control range and higher than their corresponding response to glucose. Arginine led to a higher stimulation than glucose, in subgroups that either progressed to diabetes $(p<0.006)$ or did not $(p<0.002)$. Finally, "low-responders" who did not develop diabetes displayed similar responses to both glucagon and arginine than "normo-responders" to glucose. A progressive decrease of arginine-stimulated insulin response may be a later event during pre-Type 1 diabetes than ablunted response to glucose, while a loss of glucagon-stimulated insulin release may be intermediate. Diminished response to all secretagogues may offer better prediction than a "low" response to glucose alone.

Key words: Acute insulin response, Type 1 (insulin-dependent) diabetes mellitus, risk, glucose, glucagon, arginine.
The chronological link and the pathogenic significance of these metabolic abnormalities remain unclear. In particular, studies on AIR to different secretagogues have led to controversy. On one hand, a decreased AIR to glucose was suggested to be coexisting with a subnormal AIR to other stimuli in pre-diabetic humans [12], and in vitro in islets of diabetes-prone non-obese diabetic (NOD) mice [13] and in BioBreeding Worcester (BB/W) rats [14]. On the other hand, alterations of glucose and glucagon-stimulated insulin release have been described in ICA positive twins of Type 1 diabetic patients [15]. Only a prospective evaluation of AIR to different secretagogues in subjects at risk for Type 1 diabetes will solve this problem. An alternative approach is to study crosssectionally individuals with various risks for developing the disease in order to evaluate the hierarchy of insulin response previously reported in early Type 1 diabetic subjects [12]. 
Table 1. Clinical and biological characteristics of the subjects studied at risk for developing Type 1 (insulin-dependent) diabetes

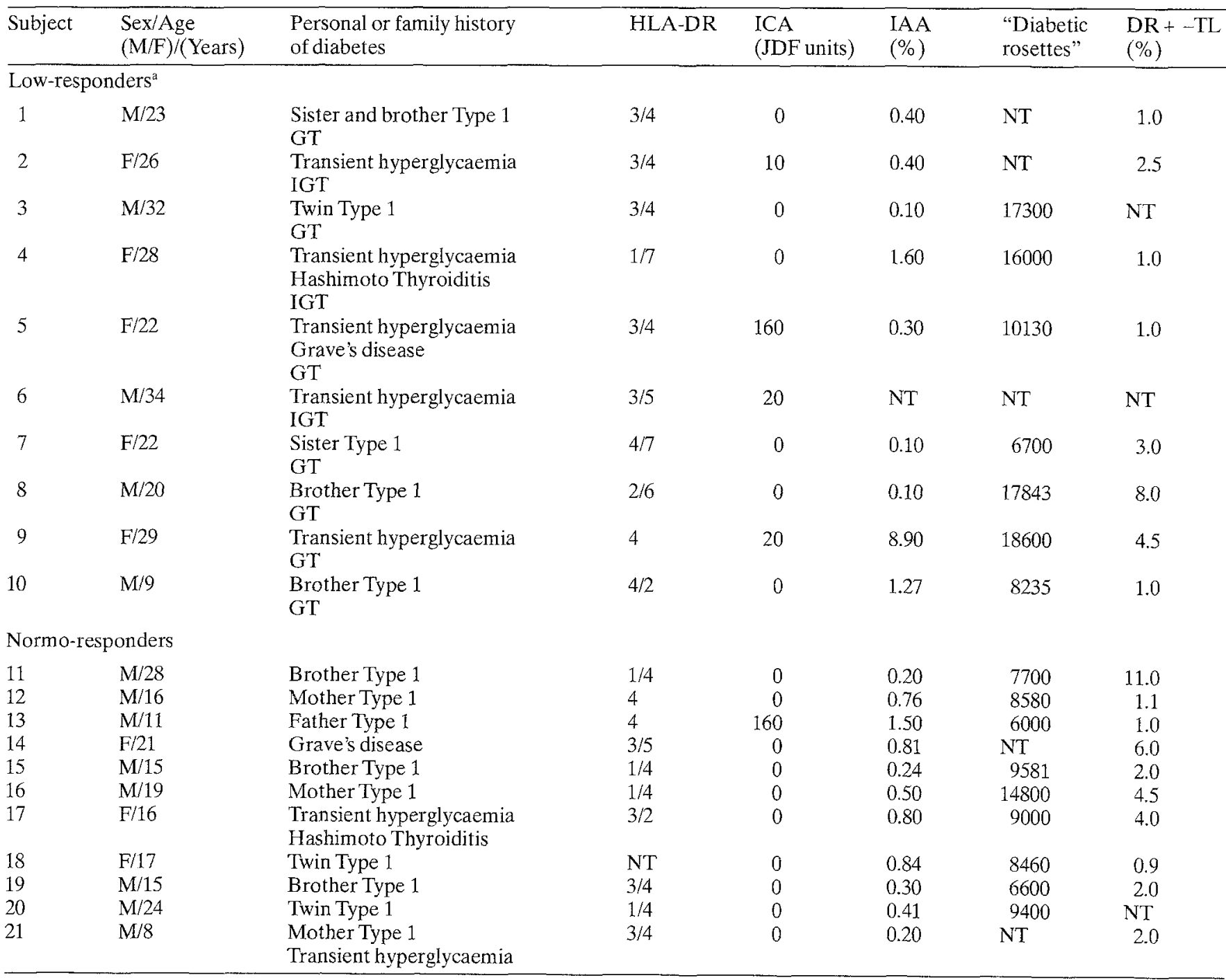

a The cutoff for a low acute insulin response to intravenous glucose is defined in "Material and Methods"

NT: not tested; GT: oral glucose tolerance; IGT: impaired oral glucose tolerance; ICA: islet-cell antibodies; JDF units: Juvenile Diabetes Foundation units; IAA: insulin autoantibodies; DR + - TL: "activated" T-lymphocytes

We have therefore evaluated AIR to intravenous glucagon and arginine in healthy adult volunteers and in subjects at risk for Type 1 diabetes, either "normal" or "low" insulin-responders to glucose. Furthermore, since the poor specificity of AIR to glucose is known [16], we have analysed these metabolic results according to the development of diabetes to investigate whether diminished responses to all three secretagogues may offer better prediction than AIR to glucose alone.

\section{Subjects, materials and methods}

\section{Subjects}

Sixty-eight healthy adult volunteers were studied. All these subjects underwent an intravenous glucose tolerance test, and the insulin responses to i.v. glucagon and i.v. arginine were evaluated in 19 randomly selected subjects (Group I). For ethical reasons, children (less than 15 years old) could not be included in this control group. Twenty-one subjects at risk for Type 1 diabetes (Group II) were also included in the study. Among this latter group, the first-phase insulin responses to glucagon and to arginine were estimated in 11 "normoresponders" (Group II a) and in 10 "low-responders" to i. v. glucose (Group IIb). A value below the mean - 2 SD of "age-related" AIRGs, previously calculated [17] in a population of 272 ICA and IAA negative relatives, aged 3 to 48 years old, of Type 1 diabetic patients, defined a "low" AIRG. The "age-related" changes of AIR to glucose have also been reported by others [18]. All the "low-responders" also had AIRG below the $5^{\text {th }}$ percentile of the 68 adult healthy control subejcts (IRI $1+3 \mathrm{~min}=35 \mu \mathrm{U} / \mathrm{ml}$ ).

Group I subjects had no personal or familial history of diabetes or autoimmune disease. Subjects of Group II were first-degree relatives of Type 1 diabetic subjects ( $n=14$ ), transient basal hyperglycaemic individuals $(n=6)$ either ICA positive or with organ-specific autoimmune disease, and one patient with Graves' disease $(n=1)$ (Table 1$)$. The transient hyperglycaemia $(>6.1 \mathrm{mmol} / \mathrm{l})$ was detected during pre-surgery screening or a medical examination. These transiently hyperglycaemic subjects had returned to fasting normoglycaemia by the time of the tests. Individuals from Groups I and II were similar in terms of sex (M/F: $10 / 9$ vs $13 / 8$ ), age (22 \pm 1 vs $21 \pm 2$ years $)$, and body mass index $\left(22.8 \pm 1.0 \mathrm{vs} 21.6 \pm 1.5 \mathrm{~kg} / \mathrm{m}^{2}\right)$. The subjects were taking no medication and consumed a diet of $250 \mathrm{~g}$ carbohydrate for 3 days prior to the tests. 

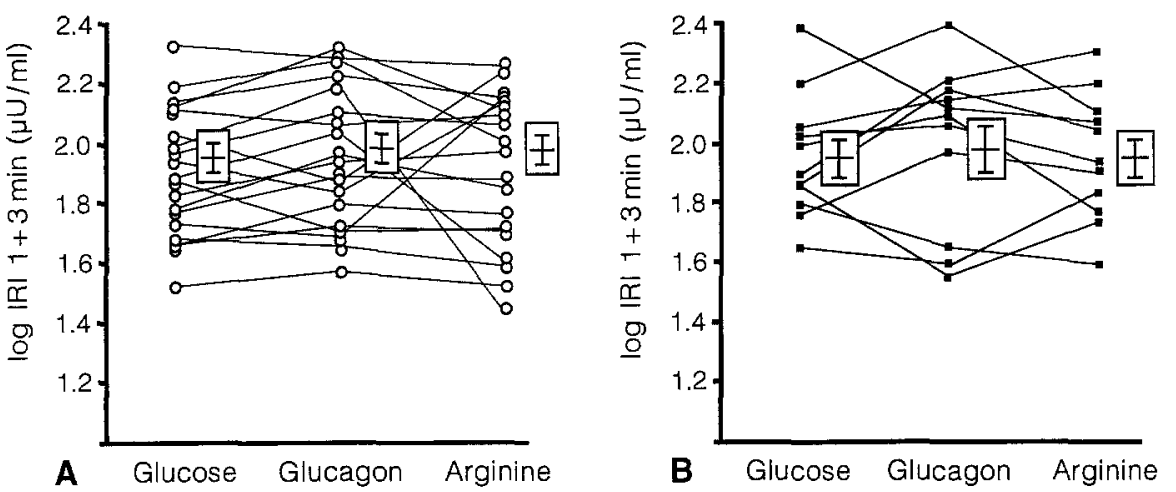

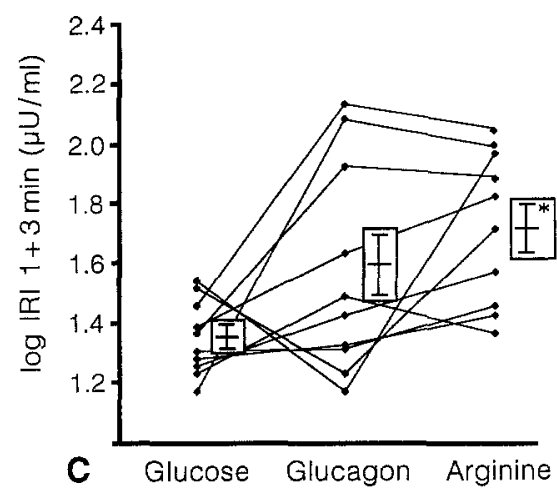

Type 1 (insulin-dependent) diabetes "normo-responders" to i. v. glucose (Group II a). Panel C: subjects at risk "low-responders" to i. v. glucose (Group IIb). * $p<0.006$ between acute insulin response to arginine and to glucose
All subjects gave their written informed consent and the studies were performed with the permission of the local ethical committee.

\section{Methods}

Metabolic studies. Acute insulin responses to i.v. glucose (AIRG), to i.v. arginine (AIRArg) and to i.v. glucagon (AIRGIn) were evaluated in this order at 2 -day intervals, on the morning after a $12 \mathrm{~h}$ overnight fast. Intravenous glucose tolerance tests were performed as previously described [10]. Briefly, catheters were inserted into both antecubital veins and $0.5 \mathrm{~g} / \mathrm{kg}$ body weight of $30 \%$ glucose was injected over $2 \mathrm{~min} \pm 5 \mathrm{~s}$. To evaluate AIRArg, $5 \mathrm{~g}$ of arginine (Veyron, Marseille, France) was diluted in $50 \mathrm{ml}$ of a $0.9 \%$ $\mathrm{NaCl}$ solution and injected over $1 \min \pm 5 \mathrm{~s}$. To evaluate AIRGln, $2 \mathrm{mg}$ of porcine glucagon (Novo, Copenhagen, Denmark) was diluted in $60 \mathrm{ml}$ of a $0.9 \% \mathrm{NaCl}$ solution and injected over $1 \mathrm{~min} \pm 5 \mathrm{~s}$. The doses of glucagon and arginine used here have been reported to induce maximal insulin release $[19,20]$. Previous studies $[19,21]$ and our unpublished data have shown that the AIR to these two secretagogues, injected as a $30 \mathrm{~s}-1$ min bolus, peaks during the $2-4 \mathrm{~min}$ period.

Blood samples were taken 10 min prior to each bolus (glucose, glucagon, arginine) and at 1 and 3 min after the end of the injection. Each sample was drawn in less than $15 \mathrm{~s}$ and kept on ice until centrifugation. Plasma was then frozen at $-20^{\circ} \mathrm{C}$. Blood glucose was measured using a glucose oxidase method. Basal and stimulated immunoreactive insulin concentrations were measured by radioimmunoassay (SB-INSI-5, International CIS, Saclay, France) with ${ }^{125} \mathrm{I}$ porcine insulin, with human insulin as a standard, and guinea pig antiserum to human insulin. Separation was carried out with polyethylene glycol. Undiluted plasma leading to immunoreactive insulin values above $60 \mu \mathrm{U} / \mathrm{ml}$ was further diluted until falling in the linear portion of the standard curve. Sensitivity of the assay was $2.5 \mu \mathrm{U} / \mathrm{ml}$; the intra- and inter-assay coefficients of variation were less than $10 \%$. Inter- and intra-individual variabilities of AIRG were previously reported in the adult healthy control subjects included in the present study [22]. Previous studies [23, 24] have reported similar coefficients of variation for AIRG, AIRGIn and AIRArg. An oral glucose tolerance test $(75 \mathrm{~g}$ glucose load for adult subjects and $1.75 \mathrm{~g} / \mathrm{kg}$ for children) was performed in "low-responders" to i.v. glucose. Impaired glucose tolerance and diabetes mellitus were defined according to the criteria of the World Health Organization.

Detection and quantification of islet-cell antibodies and insulin-autoantibodies. Sera were tested in a blinded manner for IgG-ICA by indirect immunofluorescence on cryostat sections of the same blood group $O$ human pancreas. One ICA positive internal standard sample and the international reference serum accepted by the Immunology of Diabetes Workshops [25] were included. Results were expressed in Juvenile Diabetes Foundation (JDF) units. Subjects were classified as ICA positive if they had at least two positive samples ( $\geq 10$ JDF units). In the Fourth International Islet-Cell Antibody Workshop, our laboratory had $100 \%$ sensitivity and $86 \%$ specificity in blinded analysis of test serum samples, with a limit of detection of 2.5 JDF units.

Sera were also tested for the presence of IAA by an immunoradiometric assay [26], using the ability of sera to bind monoiodinated ${ }^{125} \mathrm{I}$ Tyr-A-14 human insulin (specific activity $250 \mu \mathrm{Ci} / \mu \mathrm{g}$, Novo, Copenhagen, Denmark). The inter- and intra-assay coefficients of variation were 15 and $10 \%$ respectively. In each assay our positive internal standard sample was included. A positive result was defined as a value $>1.3 \%$, i.e. $>3 \mathrm{SD}$ above the mean binding of control sera $(0.94 \pm 0.12 \%)$. These control sera displayed normally distributed values. The sensitivity of the assay was $0.15 \%$.

Detection of "activated" T-lymphocytes $(D R+-T L)$. The percentage of circulating "activated" HLA-DR positive T-cells was determined by a direct two-colour immunofluorescence technique as previously described [27]. The level of positivity was defined as the mean value +2 SD of controls (i.e. $4 \%$ ).

RIN cell-binding lymphocytes in vitro. The detection of lymphocytes binding to rat insulinoma (RINm5F) cells was performed as previously described $[27,28]$. The increased number of RIN-adherent lymphocytes in diabetic as compared to control subjects are called "diabetic rosettes". A positive test was arbitrarily defined as a value of RIN-adherent lymphocytes higher than the $95^{\text {th }}$ percentile of 300 control subjects $(15,000)$. In each experiment, subjects at risk were tested in triplicate, with at least two control subjects. Intra-assay variability was less than $10 \%$ and inter-assay variability did not exceed $15 \%$. The assay was performed in a blinded manner.

HLA typing. Lymphocytes from blood samples were typed for HLA-DR antigens by the two-colour immunofluorescence technique.

\section{Statistical analysis}

AIRG, AIRGln, and AIRArg were calculated as the sum of $1+3$ min insulin values and $\log$-transformed for the purpose of statistical analysis because of an abnormal distribution of insulin values. Differences were evaluated by the non-parametric KruskalWallis test when three populations were compared. Two-tailed Student's $t$-tests were used for comparison of two sets of data, paired or unpaired when appropriate. Simple regression analysis was used to evaluate correlations between AIRG and AIRGln, AIRG and AIRArg, AIRGln and AIRArg. $p<0.05$ was taken as significant. 


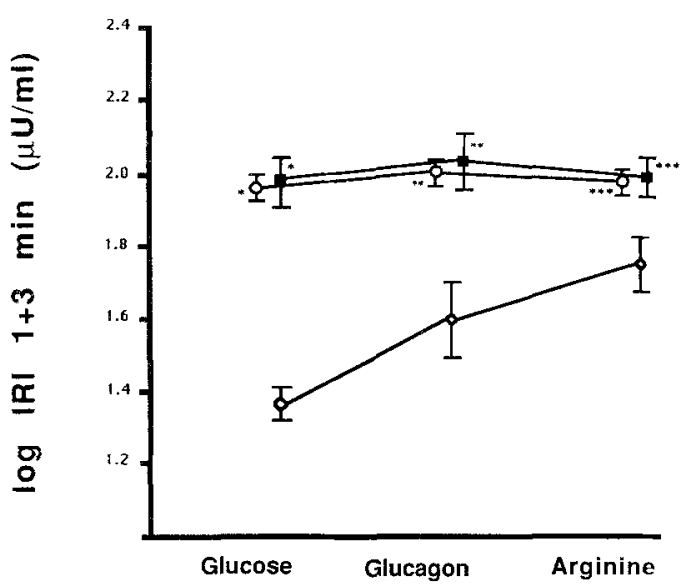

Fig.2. Acute insulin response to i.v. glucose, glucagon and arginine, expressed as mean values \pm SEM of $\log$ immunoreactive insulin (IRI) $1+3 \mathrm{~min}(\mu \mathrm{U} / \mathrm{ml})$, in group I (O), II a $(\mathbf{a})$, and IIb $(\diamond)$. The statistical differences are indicated between Group II $b$ and the two other groups. * $p<0.0001 ; * * p<0.007 ; * * * k<0.04$

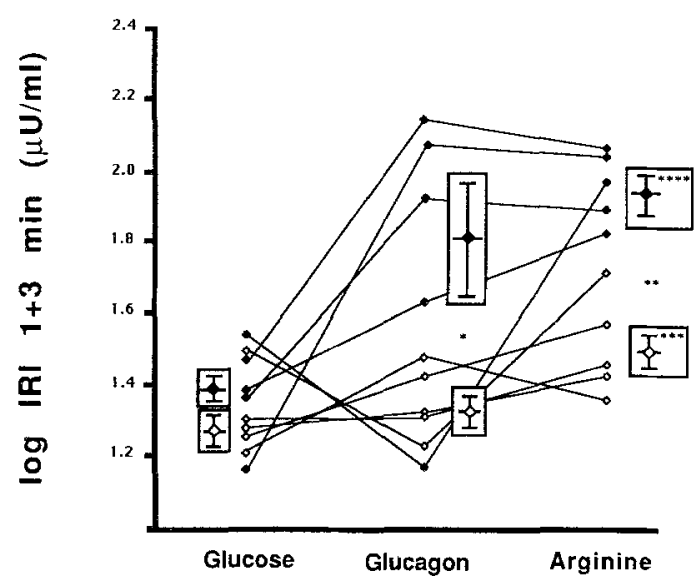

Fig.3. Acute insulin response to i.v. glucose (AIRG), glucagon (AIRGIn) and arginine (AIRArg), expressed as log immunoreactive insulin (IRI) $1+3 \mathrm{~min}(\mu \mathrm{U} / \mathrm{ml}$ ) in subjects at risk "low-responders" to glucose (Group II b), who have progressed to Type 1 (insulin-dependent) diabetes $(\diamond)$, or have not $(\diamond)$. Vertical bars denote mean values \pm SEM. Asterisks indicate the statistical differences in insulin responses to a given stimulus between these two subgroups (For AIRGIn: * $p<0.05$; for AIRArg: ** $p<0.0003$ ). The statistical differences between AIRG and AIRArg are also indicated in each subgroup $(* * * 0<0.006 ; * * * * 0<0.002)$

\section{Results}

Acute insulin responses to glucose, glucagon and arginine within each group of subjects (Fig. 1)

In 19 adult healthy control subjects (Group I), no statistical difference was observed between AIRG, AIRGIn and AIRArg (Fig.1A). Similarly, 11 subjects at risk for Type 1 diabetes, "normo-responders" to glucose (Group IIa) displayed similar AIRG, AIRGln and AIRArg (Fig. 1B).

By contrast, in 10 subjects at risk for Type 1 diabetes classified as "low-responders" to glucose (Group IIb), AIRG, AIRGin and AIRArg were statistically different (Kruskal-Wallis: $p<0.02$ ) (Fig.1C). Overall, AIRArg was statistically higher than AIRG $(p<0.006)$. AIRGIn tended to be more elevated than AIRG, although not significantly $(p<0.11)$, and AIRGln and AIRArg were not statistically different (Fig. 1C).

\section{Comparison of insulin responses to the three secretagogues between the three groups of subjects (Fig.2)}

By definition, "low-responders" to glucose had lower AIRG than control subjects $(p<0.0001)$ and than "normo-responders" $(p<0.0001)$. AIRG was similar in control subjects and in "normo-responders" (Fig. 2).

The mean values of AIRGIn were similar in control subjects and in subjects at risk "normo-responders" to glucose. By contrast, AIRGIn was statistically lower in "lowresponders" than in control subjects $(p<0.007)$ or in "normo-responders" $(p<0.007)$ (Fig. 2).

Similarly, AIRArg was statistically lower in "low-responders" than in control subjects $(p<0.04)$ and in "normo-responders" ( $p<0.04)$, even though fasting glycaemia was slightly higher $(p<0.01)$ in "low-responders" $(5.4 \pm 0.1 \mathrm{mmol} / \mathrm{l})$ than in "normo-responders" $(5.0 \pm 0.1)$ and than in control subjects $(4.9 \pm 0.1)$. No statistical difference was observed between control subjects and "normo-responders" in terms of AIRArg (Fig.2).

Finally, AIR to the three secretagogues were correlated in the overall population (control subjects and subjects at risk) $(p<0.0001)$, or within control subjects $(p<0.001)$ and "normo-responders" $(p<0.01)$ considered separately. By contrast, no correlation was found between AIRG, AIRGln, AIRArg in "low-responders" to glucose.

\section{Insulin responses to the three secretagogues and progression to diabetes}

Five subjects at risk eventually developed Type 1 diabetes (Table 2). All were initially classified as "low-responders" to glucose during at least two IVGTTs, and two out of five had impaired glucose tolerance (Table 1). By contrast, none of the subjects at risk with a "normal" response to glucose became insulin-dependent within a mean followup of 9 months (6-16 months).

No statistical difference was found in terms of AIRGIn or AIRArg between the five "low-responders" who have not developed diabetes and "normo-responders" to glucose. In these five subjects, no statistical difference could be detected between mean values of AIRGln and AIRG. However, four of these five subjects had AIRGln within the range of the control subjects $(39-209 \mu \mathrm{U} / \mathrm{ml})$ and higher than the corresponding individual AIRG values (Fig. 3).

The mean values of AIRGIn and AIRArg initially noted in the five "low-responders" who subsequently developed Type 1 diabetes, were statistically lower than in the other five "low-responders" who have not become diabetic ( $p<0.05$ and $p<0.0003$ respectively) (Fig. 3). In the subjects who became diabetic, AIRGin and AIRG were similar. In each of these two subgroups that either 
Table 2. Acute insulin response to glucose (AIRG), to glucagon (AIRGln) and to arginine (AIRArg) in subjects who developed Type 1 (insulin-dependent) diabetes mellitus

\begin{tabular}{llllr}
\hline Subject & $\begin{array}{l}\text { AIRG } \\
\text { Basal glycaemia/IRI 1 }+3 \mathrm{~min} \\
(\mathrm{mmol}) /(\mu \mathrm{U} / \mathrm{ml})\end{array}$ & $\begin{array}{l}\text { AIRGIn } \\
\text { Basal glycaemia/IRI } 1+3 \mathrm{~min} \\
(\mathrm{mmol} / \mathrm{l}) /(\mu \mathrm{U} / \mathrm{ml})\end{array}$ & $\begin{array}{l}\text { AIRArg } \\
\text { Basal glycaemia/IRI 1 +3 min } \\
(\mathrm{mmol} / \mathrm{l}) /(\mu \mathrm{U} / \mathrm{ml})\end{array}$ & $\begin{array}{l}\text { Months } \\
\text { to development } \\
\text { of diabetes }\end{array}$ \\
\hline 2 & $5.2 / 16$ & $5.7 / 29$ & $5.2 / 22$ & 6 \\
3 & $5.8 / 17$ & $5.5 / 25$ & $5.7 / 35$ & 24 \\
4 & $4.7 / 18$ & $4.8 / 20$ & $5.6 / 27$ & 12 \\
5 & $5.8 / 19$ & $5.8 / 20$ & $5.9 / 25$ & 6 \\
9 & $6.0 / 31$ & $5.8 / 16$ & $5.7 / 49$ & 14 \\
\hline
\end{tabular}

IRI = immunoreactive insulin

developed diabetes or did not, AIRArg was higher than AIRG $(p<0.006$ and $p<0.002$ respectively) (Fig. 3). Before the evaluation of AIRArg, fasting glucose values were not different between "low-responders" who developed diabetes $(5.6 \pm 0.1 \mathrm{mmol} / \mathrm{l})$ and those who did not $(5.3 \pm 0.2)$, although they were in the upper part of the normal range $(4.9 \pm 0.1)$.

Although low responses to the three secretagogues announced the imminence of diabetes (6-24 months), an absolute response to any of the stimuli did not predict the precise delay to the disease (Table 2).

\section{Discussion}

Control subjects respond similarly to glucose, glucagon and arginine. As our experiment to stimulate insulin secretion used doses of each secretagogue known to induce maximal release $[19,20]$, this suggests that any change of insulin response to different secretagogues in subjects at risk may not be attributable to variations in the insulin secretory efficacy from one stimulus to another. Subjects at risk "normo-responders" to glucose demonstrate similar responses to glucagon and arginine to those of the control subjects. In contrast, irrespective of the development of the disease, "low-responders" to glucose display significantly reduced AIR to both glucagon and arginine. However, AIR to arginine remains higher than AIR to glucose in these "low-responders". Interestingly, "low-responders" who did not develop diabetes respond similarly to glucagon and arginine than control subjects. In contrast, "low-responders" who further progressed to the disease (true pre-diabetic subjects) had a low response to the three secretagogues, although slightly less impaired to arginine.

The low insulin response to i.v. glucose seems to be a sensitive indicator of pre-diabetes $[10,16,17]$ and may increase the predictive value of ICA positivity [17]. In this respect, all our subjects who went on to develop diabetes displayed this metabolic abnormality.

In our study, insulin responses to glucagon and glucose seem to be closely related, while "low-responders" to glucose still had some response to arginine. Since the three stimuli act differently on the Beta cell, this suggests on one hand that a specific functional abnormality of insulin secretion may account for a "low response" to glucose. This hypothesis may be in accordance with data obtained in early Type 1 diabetes [12], or in vitro in diabetes-prone
NOD mice [13] and $\mathrm{BB} / \mathrm{W}$ rats [14]. Is this phenomenon related to antibodies directed against Beta-cell glucose transporters in recent-onset diabetic patients [29] or $\mathrm{BB} / \mathrm{W}$ rats in which a quantitative defect in GluT 2 transporters has been also demonstrated? [30] On the other hand, our study shows that insulin responses to glucagon, and even to arginine, are lower than those observed in control subjects. This suggests that the insulin secretory capacity, i.e. the Beta-cell mass, may be also affected. Both a functional Beta-cell defect and a decreased Betacell mass may thus be relevant to the loss of AIRG in the present "low-responders".

However, the "low-responders" to glucose are a heterogeneous group, since only one subgroup has developed diabetes. Some "low-responders" to glucose have not progressed to the disease at least during a short-term follow-up of 32 months (22-40 months). In these subjects, a differential response was found to the three stimuli. In particular, an arginine response was preserved as it was also described in islets from diabetes-prone $\mathrm{BB} / \mathrm{W}$ rats [30]. On one hand, this may confirm that risk for the disease is associated with a specific functional alteration of the Beta cell. Even if responses to glucagon and to glucose were not statistically different in this "low responder" group that has not progressed to diabetes, it remains possible that a differential response to glucagon and glucose could occur at some stage which our cross-sectional study would not detect. In support of this hypothesis, four out of these five patients still showed a response to glucagon within the normal range. On the other hand, one can question whether these subjects are really at risk for Type 1 diabetes since the specificity of AIRG for the disease in the absence of other risk markers is poor [16]. Among the five "low responders" who did not become diabetic, only one had ICAs which remain the best operational markers for pre-Type 1 diabetes. Nevertheless, the other subjects displayed either genetic markers or high levels of "activated" and RIN-cell binding-lymphocytes, even if this latter test seems to be quite sensitive but less specific for the development of the disease [27].

The subgroup who progressed to diabetes displayed a blunted AIR to glucose and to glucagon months before the onset of clinical symptoms of the disease. The response to arginine, even if present was also dramatically affected in these patients. Two hypotheses may account for the less severe impairment of the response to arginine. Firstly, the decreased response to arginine may be 
a late event during pre-Type 1 diabetes. This will be highlighted by a follow-up of high risk subjects (i.e. high-titre ICA-positive glucose-tolerant relatives) who may be more suitable subjects in which to study the evolution of AIR to various secretagogues than transiently hyperglycaemic subjects who are probably very close to onset of diabetes [12]. Two out of five patients who went on to develop diabetes had impaired glucose tolerance at the time of the intravenous tests. On the other hand, the fasting glucose values of pre-diabetic "low-responders" to glucose are in the upper part of the normal range and may have accounted for a sensitisation of Beta cells to arginine.

Nevertheless, from a practical point of view, the finding of inappropriate responses to glucagon and arginine may enhance the risk for the disease as compared to a "low" response to glucose alone. Our study even suggests that "low" responses to the three stimuli announce the impending onset of diabetes which appeared 6 to 24 months later (less than one year in four out of five subjects), although an absolute response to any secretagogue does not predict the precise delay to the disease.

Acknowledgements. The authors are grateful to the other members of the GOFEDI (Groupe Ouest-France pour l'Etude du Diabète Insulino-dépendant): Drs. L. Martignat, E. Gouin (Laboratoire d'Immunologie du Diabète, Nantes), J.D.Bignon, A. Vergracht (Centre de transfusion sanguine, Nantes), M. Kremer (Laboratoire Isotopes, Nantes), D.Antonioli, J.P.Lemort (Statistiques, Nantes), M. G. Joseph (Pédiatrie, Angers), E. Mathieu, Y.Gallois, A. Giraud, (Laboratoire de Biochimie, Angers), A. Pouplard (INSERM U.298, Angers), B.Coueffic (Centre de Transfusion Sanguine, Angers), M.Delamaire, R. Fauchet, N. Genetet, (Centre de Transfusion Sanguine, Rennes). This work was supported by grants from INSERM (Contrat de recherche externe; Réseau de recherche clinique), Caisse Régionale d'Assurance Maladie de Loire-Atlantique, and Direction Régionale de l'Action Sanitaire et Sociale des Pays de Loire.

\section{References}

1. Eisenbarth GS (1990) Multiple target antigens in pre type 1 diabetes. Implications for prediction. Horm Res 33: 144-153

2. Tarn AC, Thomas JM, Dean BM, Ingram D, Schwarz G, Bottazzo GF, Gale EAM (1988) Predicting insulin-dependent diabetes. Lancet I: $845-850$

3. Bonifacio E, Bingley PJ, Shattock M, Dean BM, Dunger D, Gale EAM, Bottazzo GF (1990) Quantification of islet-cell antibodies and prediction of insulin-dependent diabetes. Lancet 335: $147-$ 149

4. Baekkeskov S, Landin M, Kristensen JK et al. (1987) Antibodies to a $64000 \mathrm{Mr}$ human islet cell antigen precede the clinical onset of insulin-dependent diabetes. J Clin Invest 79: 926-934

5. Atkinson MA, McLaren NK, Scharp DW, Lacy PE, Riley WJ (1990) $64000 \mathrm{Mr}$ autoantibodies as predictors of insulin-dependent diabetes. Lancet 335: 1357-1360

6. Dean BM, Becker F, McNally JM, Tarn AC, Schwartz G, Gale EAM, Bottazzo GF (1986) Insulin autoantibodies in the prediabetic period: correlation with islet cell antibodies and development of diabetes. Diabetologia 29: 339-342

7. Ziegler AG, Ziegler R, Vardi P, Jackson RA, Soeldner JS, Eisenbarth GS (1989) Life-table analysis of progression to diabetes of antiinsulin autoantibody-positive relatives of individuals with type 1 diabetes. Diabetes 38: 1320-1325
8. Bleich D, Jackson RA, Soeldner JS, Eisenbarth GS (1990) Analysis of metabolic progression to type 1 diabetes in $\mathrm{ICA}^{+}$relatives of patients with type 1 diabetes. Diab Care 13:111-118

9. Beer SF, Heaton DA, Alberti KGMM, Pyke DA, Leslie RDG (1990) Impaired glucose tolerance precedes but does not predict insulin-dependent diabetes mellitus: a study in identical twins. Diabetologia 33: 497-502

10. Srikanta S, Ganda OP, Gleason RE, Jackson RA, Soeldner JS, Eisenbarth GS (1984) Pre type 1 diabetes: linear loss of beta-cell response to intravenous glucose. Diabetes 33: 717-720

11. McCulloch DK, Raghu PK, Johnston C et al. (1988) Defects in $\beta$-cell function and insulin sensitivity in normoglycemic streptozotocin-treated baboons: a model of preclinical insulin-dependent diabetes. J Clin Endocrinol Metab 67: 785-792

12. Ganda OP, Srikanta S, Brink SJ, Morris MA, Gleason RE, Soeldner JS, Eisenbarth GS (1984) Differential sensitivity to beta-cell secretagogues in "early", type 1 diabetes mellitus. Diabetes 33: 516-521

13. Strandell E (1990) Different sensitivity to glucose compared to other beta-cell secretagogues in female NOD mouse islets. Diabetologia 33 [Suppl]: A95 (Abstract)

14. Tominaga M, Komiya I, Johnson JH et al. (1986) Loss of insulin response to glucose but not arginine during the development of autoimmune diabetes in $\mathrm{BB} / \mathrm{W}$ rats: relationships to islet volume and glucose transport rate. Proc Natl Acad Sci USA 83: 9749 9753

15. Heaton DA, Lazarus NR, Pyke DA, Leslie RDG (1989) B-cell response to intravenous glucose and glucagon in non-diabetic twins of patients with Type 1 (insulin-dependent) diabetes mellitus. Diabetologia 32: 814-817

16. Vialettes B, Mattei-Zevaco C, Badier C, Ramahandridona G, Lassman-Vague V, Vague $P(1988)$ Low acute insulin response to intravenous glucose. A sensitive but non-specific marker of early stages of Type I (insulin-dependent) diabetes. Diabetologia 31: 592-596

17. Joseph MG, Bardet S, Stetieh H et al. (1990) Age-related changes of acute insulin response to IV glucose (AIRG) in subjects at risk for Type 1 diabetes and progression to diabetes in ICA + IAA + subjects. Diabetologia 33 [Suppl]: A183 (Abstract)

18. Smith CP, Williams AJK, Thomas JM et al. (1988) The pattern of basal and stimulated insulin responses to intravenous glucose in first-degree relatives of Type 1 (insulin-dependent) diabetic children and unrelated adults aged 5 to 50 years. Diabetologia 31: $430-434$

19. Snorgaard O, Hasselstrom K, Lumholtz IB, Thosteinsson B, Siersbaek-Nielsen K (1988) Insulin/C-peptide response to intravenous glucagon. A dose-response study in normal and noninsulin dependent diabetic subjects. Acta Endocrinol 117: 109115

20. Van Haeften TW, Voetberg GA, Gerich JE, Van Der Veen EA (1989) Dose-response characteristics for arginine-stimulated insulin secretion in man and influence of hyperglycemia. J Clin Endocrinol Metab 69: 1059-1064

21. Palmer JP, Benson JW, Walter RM, Ensinck JW (1976) Argininestimulated acute phase of insulin and glucagon secretion in diabetic subjects. J Clin Invest 58: 565-570

22. Bardet S, Pasqual C, Maugendre D, Remy JP, Charbonnel B, Sai $P$ (1989) Inter and intra individual variability of acute insulin response during intravenous glucose tolerance tests. Diabète et métabolisme 15:224-232

23. Gjessing HJ, Damsgaard EM, Matzen LE, Froland A, Faber OK (1987) Reproducibility of $\beta$-cell function estimates in non-insulin-dependent diabetes mellitus. Diab Care 10: 558-562

24. McCulloch DK, Klaff LJ, Kahn SE et al. (1990) Nonprogression of subclinical $\beta$-cell dysfunction among first-degree relatives of IDDM patients. 5-yr follow-up of the Seattle family study. Diabetes 39: 549-556

25. Bonifacio R, Dawkins RI, Lernmark $\AA$ (1987) Report of the second international workshop on the standardization of cytoplasmic islet cell antibodies. Diabetologia 30:273 
26. Palmer JP, Asplin CM, Clemons P, Lyen K, Tatpati O, Raghu PK, Pacquette TL (1983) Insulin antibodies in insulin dependent diabetics before insulin treatment. Science 222: 1337-1339

27. Bardet S, Rohmer V, Maugendre D et al. (1990) Beta-cell cytoadherent lymphocytes in some subjects at risk for type 1 (insulindependent) diabetes: progression to diabetes within 2 years. J Clin Endocrinol Metab 71:1310-1317

28. Lang F, Maugendre D, Houssaint-Chalmeau E, Charbonnel B, Saï $\mathrm{P}$ (1987) Cytoadherence of lymphocytes from type 1 diabetics to insulin secreting cells: a marker of anti beta-cell cellular immunity. Diabetes 36: 1356-1364

29. Johnson JH, Crider BP, McCorkle K, Alford M, Unger RH (1990) Inhibition of glucose transport into rat islet cells by immunoglobulins from patients with new-onset insulin-dependent diabetes mellitus. NEngl J Med 322: 653-659
30. Orci L, Unger RH, Ravazzola M et al. (1990) Reduced beta-cell glucose transporter in new onset diabetic $\mathrm{BB}$ rats. J Clin Invest 86: $1615-1622$

Received: 2 January 1991

and in revised form: 26 April 1991

\section{Dr. P.Saï}

Laboratoire d'Immunologie du Diabète

Faculté de Médecine

1 rue Gaston Veil

F-44035 Nantes

France 